era's ideas about how the exercise of 'self-mastery' in relations between men and boys contributed to the production of appropriate masculinity. And, as would be expected, she recognizes that the modern construction of the figure of the homosexual is linked to what Laqueur (1990) has identified as the creation of two separate sexual spheres.

Less positively, although the subject matter is interesting, contrary to the publisher's blurb, I did not find the book 'a compelling read'. Partly this is a problem related to the publisher's style and layout but Hawkes' writing style also at times feels laboured rather than engaging.

Feminist insights are included but are not central, and where power is discussed it is not as often as might be expected identified as gendered or racialized. Issues of ethnic diversity are absent, and while this is of course a text on a predominantly Caucasian culture, one would expect some mention of how the ideas she invokes are connected to an imperialist project involving distorted ideas about the sexuality of non-white people.

But these criticisms apart, Sex and Pleasure in Western Culture will provide a useful introduction to ideas about sexuality for students, academics and general readers.

\title{
reference
}

Kristin Aune

Laqueur, T. (1990) Making Sex: Body and Gender from the Greeks to Freud, Cambridge, MA: Harvard University Press.

doi: $10.1057 /$ palgrave.fr. 9400369

\section{Violence and the body: race, gender, and the state}

Arturo J. Aldama (editor); Indiana University Press, Bloomington, Indiana, 2003, 400p, ISBN 0-253-21559-5, £21.50 (Pbk); ISBN 0-253-34171-X, £57.00 (Hbk)

In 'On The Subject of Violence', Roland Barthes (1985) asserts that 'one must choose one's key to discuss violence'. In editor Arturo J. Aldama's collection of 23 essays, Violence and the Body: Race, Gender and the State, 'the body' is offered as such a key. In his introduction, Aldama states his intention to 'create a dialogic space to explore the relationships between discursive violence' and the 'materiality of violence'. The book provides 'an alternative political and theoretical space where feminist work on the social construction of the body' can intersect with 'women of color theories of the multiplicity of oppression and 
resistance' to 'discern the materiality of physical and representational violence on the "otherized" body' (p. 5). The essays collected are disparate in epistemology and in object, yet a tendency to apply post-structural textual analysis to real and fictional objects predominates. While interesting in several respects detailed below, overall what emerges is a generally directionless series of meditations on sub-alterity suggesting that the critical coupling is more demanding than it would first appear.

In cultural studies and feminist trans-disciplinary theorizing, 'the body' has been called into service to suture disparate critical currents. The body enters where discrete analyses of specific interpellations (e.g. ethnicity, race, gender, sexuality) falter in the face of complex intersectionality. Burdened as it is by multiple inscriptions, the body grounds confrontations between the material and symbolic in specific arrangements of power and knowledge. It is a productive abstraction as it gives way to critical specificity as soon as it is invoked. The problem is that, even with the advantage of a recent critical canon, 'the body' cannot anchor, and cannot be anchored by, 'violence'. 'Violence', like 'the body', is a complicated term. Like the body, violence serves to define and complicate the boundary between the material and the symbolic. Similarly, any substantive engagement with the question of violence demands specificity. The majority of contributors in Aldama's collection demonstrate their critical competence with the body alongside comparative critical neglect of violence as a concept. There is confidence regarding the body and its construction but violence is seldom more than an instrument that serves to inscribe culture upon the body, which thus serves as a kind of text.

That violence would do more than merely subject seems a problem that poststructuralist criticism is well equipped to consider. While there are glimpses of such complexity throughout the collection, the insight is developed in only the most directly theoretical or the most empirically grounded offerings. In Elizabeth Grosz's discussion of Derrida, 'The Time Of Violence', she states outright that 'it is no longer clear (if it ever was) that one can distinguish between a "good" and a "bad" violence.' For Grosz, we need to 'refuse the knee-jerk reactions' of 'outright condemnation before we understand the structure and history of the modality of violence' (p. 141). While the relevant signposts of corporeal feminism and post-colonial theory are prevalent throughout the collection, engagement with prominent theorists of violence who might aid such an elaboration, even those that reconcile with those prevalent theoretical frames (Elaine Scarry? Michael Taussig?) are sparsely mentioned. The history and modality of violence, its technological complexity, are undeveloped. Without such a parallel theorization, violence can only lend suspect weight to otherwise competent analyses of power.

William Anthony Nericcio's essay on Rita Hayworth, 'When Electrolysis Proxies for the Existential' refuses any such claim to analytical authority and thus brings 
into relief the political confidence that characterizes other contributions to the collection. Nericcio's essay - dry, flip and sarcastic - is aware of the limitations of theory in the face of violence and death and knowingly reminds us not to 'overestimate the effect of our textual labor' (p. 265). Less awed by the political urgency and grave import of writing on violence Nericcio is perhaps released in such a way that allows him a more nuanced approach. Violence does not just subject and inscribe the body that becomes Rita Hayworth: it animates that body. The productivity of violence emerges alongside its repressive capacity. Nericcio's 'Ritarcheology' charts a subject so immersed in competing forces of violence that the body one might wish to liberate is certainly lost, if it ever existed. Hayworth starkly represents a mournful state of affairs where the historical and cultural pervasion of violence subtends subjectivity in such a fashion as to make our repulsion for violence seem a little naïve. This does not recommend nihilistic abandon so much as it suggests the amount of critical work still required for any politically productive understanding of violence in relation to the body.

The densely theorized offerings of Grosz and Nericcio ironically point us to the more empirical, more historically and sociologically grounded, essays in the collection as the relevant starting points for a productive consideration of violence and the body. Less mired in the textual-discursive constellation of violence and the body, such efforts discover the complicated and specific operations of violence that Grosz and Nericcio both emphasize. Yamuna Sangarasivam's anthropological account of the manner in which militarization of Tamil nationalist women serves to transform broader gender scripts complicates the conceptualization of violence as repressive in compelling and disturbing ways. Leila Neti's analysis of the 'no wash' protest undertaken by women in Armagh Prison offers instances of selfsubjugation arguably producing effective subjectivations. Similarly, Elaine $\mathrm{H}$. Kim's discussion of Korean-American women's complicated negotiation of two states, and Yvette Flores-Ortiz's discussion of Latina women's negotiation of violence across the social, the familial and the self, represent the most theoretically straightforward yet critically adept additions to an understanding of violence and the body and thus successfully occupy Aldama's exploratory space.

\section{reference}

David Hansen-Miller

Barthes, R. (1985) 'On the subject of violence' in The Grain of the Voice; Interviews 1962-1980, Translated by Coverdale, L., Berkley: University of California Press, 306-311 (p. 308).

doi: $10.1057 /$ palgrave.fr. 9400372 